\title{
Current challenges in visibility improvement in southern China
} Wanyun Xu' ${ }^{1}$ Ye Kuang ${ }^{2,3, *}$, Yuxuan Bian ${ }^{4}$, Li Liu ${ }^{5}$, Fei Li ${ }^{5}$, Yaqiang Wang ${ }^{6}$, Biao Xue ${ }^{2,3}$, Biao Luo $^{2,3}$, Shan Huang ${ }^{2,3}$, Bin Yuan ${ }^{2,3}$, Pusheng Zhao ${ }^{7, *}$, Min Shao ${ }^{2,3}$

$4 \quad{ }^{1}$ State Key Laboratory of Severe Weather, Key Laboratory for Atmospheric Chemistry, Institute 5 of Atmospheric Composition, Chinese Academy of Meteorological Sciences, Beijing, 100081, 6 China

$7 \quad{ }^{2}$ Institute for Environmental and Climate Research, Jinan University, Guangzhou, China.

$8{ }^{3}$ Guangdong-Hongkong-Macau Joint Laboratory of Collaborative Innovation for Environmental 9 Quality, Guangzhou, China.

$10{ }^{4}$ State Key Laboratory of Severe Weather, Chinese Academy of Meteorological Sciences, Beijing, 11 100081, China

125 Institute of Tropical and Marine Meteorology, China Meteorological Administration, 13 Guangzhou, 510640, China

$14{ }^{6}$ Artificial Influence Weather Center, Chinese Academy of Meteorological Sciences, Beijing, 15 100081, China

$16{ }^{7}$ Institute of Urban Meteorology, China Meteorological Administration, Beijing 100089, China

17 Corresponding author: Ye Kuang (kuangye@jnu.edu.cn) and Pusheng Zhao (pszhao@ium.cn) 
Confidential manuscript submitted to Environmental Science and Technology Letters

42

43

44

45 


\section{Table of content}

1. Supplementary Methods

1.1 Deduction of the relationship between visibility and PM2.5 ........................................4

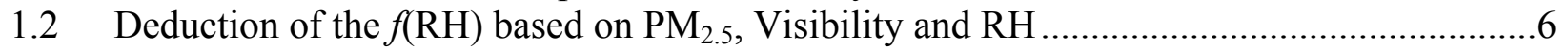

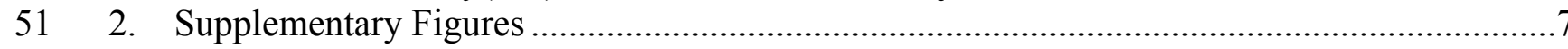

52 Figure S1 NCDC ISD stations with PM2.5 measurements available in China. Sites within the 53 two blue rectangles have used to represent the PRD and NCP region. ....................................7 7

Figure S2 (a) Yearly variation of $\mathrm{NO}_{2}$, (b) Probability distribution of $\mathrm{NO}_{2}$ for years 2013 to 2018

Figure S3 (a) The simulated $\underline{\sigma s p}, \underline{P M 2.5}$ and $\underline{\sigma \text { coarse }}$ using particle number size distributions of PM10 measured at eight sites on the North China Plain; (b) The Probability distribution of ocoarse (black line) and its fraction (red line) to $\underline{\sigma s p}, \underline{P M 2.5}$.

\section{7}

Figure S4. The relationship between mass concentrations of PM2.5 and BC at a) HeShan and b)

60 Gucheng 2016.

61 Figure S5. Frequency distribution of a) visibility, b) $\mathrm{PM}_{2.5}$ and c) RH in the PRD (blue) and

62 NCP (green) regions between 2013 and 2018.

63 Figure S6 Number of data points under different RH and visibility ranges for NCP and PRD

65 Figure S7. Variation of visibility with PM2.5 and a) aerosol optical hygroscopicity parameter $\left(\kappa_{\text {sca }}\right)$, b) aerosol density $\left(\rho_{\mathrm{a}}\right)$ and c) Volume scattering efficiency (VSE) ......

67 Figure S8. (a) Aerosol scattering efficiency $Q_{\text {sca }}$ (black) and volume scattering efficiency (red)

68 as a function of particle diameter (units of $\mathrm{Mm}^{-1} \mu \mathrm{m}^{-3} \mathrm{~cm}^{3}$ ); (b) normalized PNSD of GC2016

69 and Heshan campaigns under different aerosol volume concentrations levels.

70 Figure S9 Changes in $\kappa_{\text {sca }}$ with varying (a) ammonium sulfate fraction among SIA, (b)

71 secondary inorganic aerosol (SIA) fraction and (c) organic aerosol hygroscopicity $\left(\kappa_{\mathrm{OA}}\right)$ 16 


\section{Supplementary Methods}

\subsection{Deduction of the relationship between visibility and PM2.5}

The correlation between observed aerosol mass concentrations and visibility was often discussed in past literature $\left({ }^{1-3}\right)$, however, none of them elucidating their physical connection in detail. From the Koschmieder relation, visibility is inversely proportional to the atmospheric extinction coefficient $\sigma_{\mathrm{ex}}{ }^{1}$ :

$$
\text { Visibility }=\frac{K}{\sigma_{e x}} \text {. }
$$

Where K represents the Koschmieder constant (a value of 3.0 is usually used by visibility meter 1), and the $\sigma_{e x}$ represents the total atmospheric light extinction at $550 \mathrm{~nm}$ which can be further be divided into the sum of its scattering and absorption components:

$$
\sigma_{\mathrm{ex}}=\sigma_{s p}+\sigma_{a b s}+\sigma_{a i r}+\sigma_{N O_{2}}
$$

Eq. S2 where $\sigma_{s p}$ and $\sigma_{a b s}$ are the aerosol scattering and absorption coefficients, $\sigma_{a i r}$ is the Rayleigh scattering by air molecules and $\sigma_{\mathrm{NO}_{2}}$ the absorption by $\mathrm{NO}_{2}$ molecules. The scattering coefficient of aerosols $\left(\sigma_{s c a}\right)$ can be linked to particulate mass concentrations of aerosols with diameters $\leq 2.5$ $\mu \mathrm{m}$ (PM2.5) using the equation:

$$
\begin{aligned}
& \sigma_{s c a}=\sigma_{\text {fine }}+\sigma_{\text {coarse }}=\sigma_{s p, P M_{2.5}(R H)}+0.036 \cdot \sigma_{s p, P M_{2.5}(d r y)}, \\
& \sigma_{s p, P M_{2.5}(R H)}=\frac{P M_{2.5}}{\rho} \cdot V S E \cdot\left(1+\kappa_{s c a} \cdot \frac{R H}{100-R H}\right)
\end{aligned}
$$

where $\rho$ is the average density of dry fine particles, VSE is the volume scattering efficiency of PM2.5 particles which is defined as $V S E=\frac{\sigma_{s p, P M_{2.5}(d r y)}}{V_{t o t, P M_{2.5}}(d r y)}, \sigma_{s p, P M_{2.5}(d r y)}$ represents scattering coefficient of $P M_{2.5}$ in dry state, $V_{t o t, P M_{2.5}(d r y)}$ represents the total volume concentration of those particles in dry state, $\kappa_{s c a}$ represents the aerosol optical hygroscopicity parameter ${ }^{4}, \sigma_{\text {coarse }}$ represents scattering coefficient of coarse dust particles for continental regions. The scattering of coarse particles is on average $3.6 \%$ of $\sigma_{S p, P M_{2.5}(d r y)}$ and its scattering enhancement factor due to hygroscopic growth is set to 1 due to low hygroscopicity of dust particles ${ }^{5}$. Thus, $\sigma_{\text {coarse }}$ is parameterized as $0.036 \cdot \sigma_{s p, P M_{2.5}(d r y)}$ (see Fig. S3).

The absorption of aerosol near visible range is mainly contributed by black carbon (BC) components. Substituting Eq. S3 and Eq. S4 into Eq. S2 and applying a mass absorption coefficient 
103 at $550 \mathrm{~nm}$ of $12 \mathrm{Mm}^{-1}\left(\mu \mathrm{g} \mathrm{m}^{-3}\right)^{-1}$ along with an empirical relationship of $[\mathrm{BC}]=\mathrm{k} \times \mathrm{PM}_{2.5}$ to

104 parameterize $\sigma_{a b s}(\mathrm{k}=0.07$ based on observations in Heshan and Gucheng, Figure S4):

$105 \quad \sigma_{a b s}=12 \cdot 0.07 \cdot P M_{2.5}=0.84 \cdot P M_{2.5}$

Eq. S5

106 The Rayleigh scattering of air molecules at $550 \mathrm{~nm}$ under standard atmospheric pressure is about

$10713 \mathrm{Mm}^{-16}$, while the $\mathrm{NO}_{2}$ absorption at $550 \mathrm{~nm}$ is calculated using $\sigma_{\mathrm{NO}_{2}}=0.33 \cdot\left[\mathrm{NO}_{2}\right]$, where

$108\left[\mathrm{NO}_{2}\right]$ represents the $\mathrm{NO}_{2}$ volume mixing ratio in units of ppb, and unit of calculated $\sigma_{\mathrm{NO}_{2}}$ is $\mathrm{Mm}^{-1}$.

109 Substituting Eq.S3-S5 into Eq.S2, the following equation can be yielded:

$\sigma_{\mathrm{ex}}=\left\{\frac{V S E}{\rho_{a}} \cdot\left[\left(1+\kappa_{s c a} \cdot \frac{R H}{100-R H}\right)+0.036\right]+0.84\right\} \cdot P M_{2.5}+0.33 \cdot\left[N O_{2}\right]+13 . \quad$ Eq. S6

111 Similar $\mathrm{NO}_{2}$ levels are found in the two regions ( $23 \mathrm{ppb}$ on average) (Fig. S2), thus

112 contributing on average only $\sim 7.5 \mathrm{Mm}^{-1}$ to total extinction. The sensitivity of visibility to $\mathrm{PM}_{2.5}$,

113 VSE, $\rho_{a}$ and $\kappa_{s c a}$ under $80 \%$ RH condition is depicted in Fig. S4. Separately looking at these

114 influencing factors, visibility seems to be most sensitive to $\mathrm{PM}_{2.5}$, especially under low PM2.5

115 concentrations. Aerosol hygroscopicity parameter typically increases during its aging process,

116 with $\kappa_{s c a}$ typically falling within the range of 0.1 to $0.35^{4}$. Higher hygroscopicity leads to

117 decreased visibility. Under extremely high hygroscopicity $\left(\kappa_{\text {sca }}=0.35\right)$, relatively low $\mathrm{PM}_{2.5}$

118 concentrations of $26 \mu \mathrm{g} \mathrm{m}^{-3}$ would already lead to "bad visibility", while moderate $\mathrm{PM}_{2.5}$ levels of

$11955 \mathrm{~g} \mathrm{~m} \mathrm{~m}^{-3}$ could bring about "extremely bad visibility". At the same time, the growth in aerosol

120 density can improve visibility under given $\mathrm{PM}_{2.5}$ levels. Aerosol density varies with aerosol

121 composition, with inorganic aerosol generally having higher density $\left(\sim 1.7 \mu \mathrm{g} \mathrm{m}^{-3}\right)$ than organic

122 aerosols, secondary organic aerosol having higher densities than primary organic aerosols. Under

123 average hygroscopicity and VSE conditions, even under the high density case of $1.8 \mathrm{~g} \mathrm{~cm}^{-3}, \mathrm{PM}_{2.5}$

124 of $38 \mu \mathrm{g} \mathrm{m}^{-3}$ would already lead to "bad visibility". VSE is also positively correlated to

125 atmospheric extinction, the threshold $\mathrm{PM}_{2.5}$ to "bad visibility" decreases from 47 to $32 \mu \mathrm{g} \mathrm{\textrm {m } ^ { - 3 }}$ with

126 VSE increasing from 5 to 8. 


\subsection{Deduction of the $f(\mathrm{RH})$ based on $\mathrm{PM}_{2.5}$, Visibility and $\mathrm{RH}$}

129

Based on Eq. $\mathrm{S} 1$ and $\mathrm{S} 6, f(\mathrm{RH})$ can be described as the following, using an average $\mathrm{NO}_{2}$ 130 concentration of $25 \mathrm{ppb}$ :

$$
\frac{3}{\text { Visibility }}=\{\mathrm{MSE} \cdot[f(R H)+0.036]+0.84\} \cdot P M_{2.5}+21.25 \text {. }
$$
We divided the data into $9 \mathrm{RH}$ bins and fitted the data in each bin to yield the mass scattering

133 efficiency (MSE $\left.=\frac{V S E}{\rho_{a}}\right)$ and $f(\mathrm{RH})$ under various $\mathrm{RH}$ conditions. $f(\mathrm{RH})$ for $\mathrm{RH} \geqslant 60 \%$ conditions 134 were used to derive according average $\kappa_{\text {sca }}$.

135 The representativeness of fitting method benefits from increased sample size. Datasets during 136 first (2013-2014) and last two years (2017-2018) were used in the fitting to reflect changes in 137 aerosol optical hygroscopicity during the study period of 2013 to 2018. 


\section{Supplementary Figures}

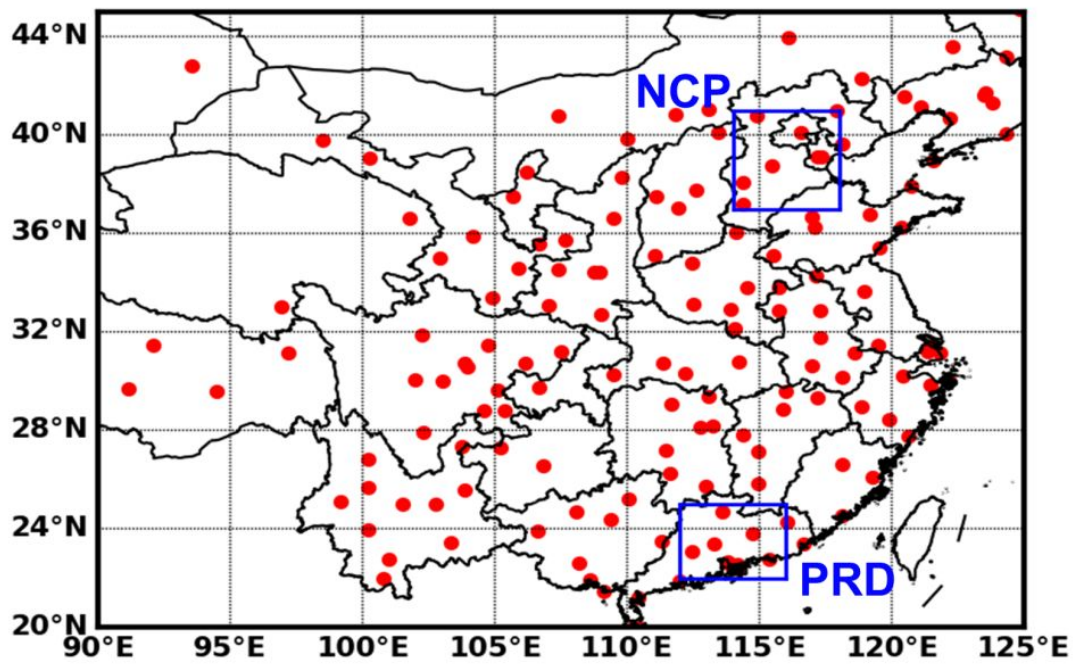

Figure S1 NCDC ISD stations with PM2.5 measurements available in China. Sites within the two blue rectangles have used to represent the PRD and NCP region. 

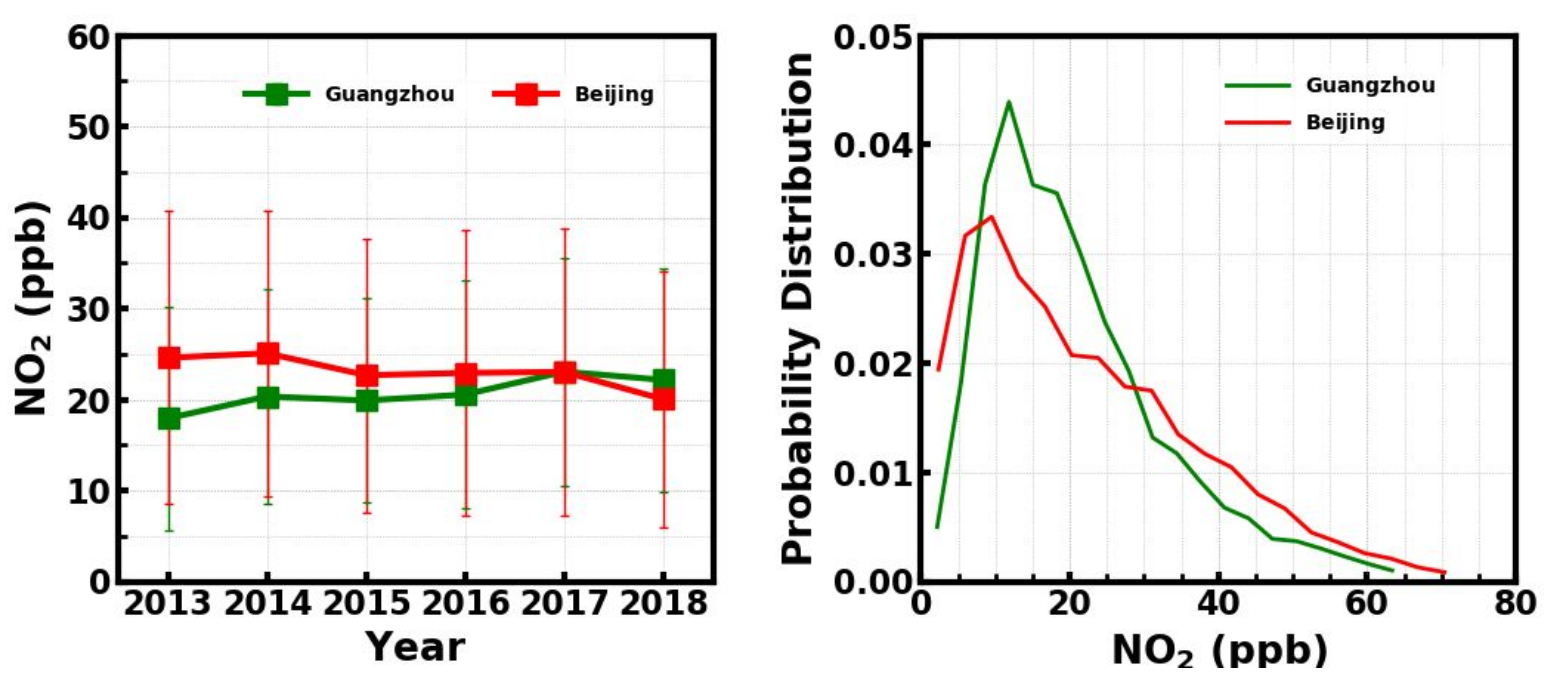

147

148

149

150

151
Figure S2 (a) Yearly variation of $\mathrm{NO}_{2}$, (b) Probability distribution of $\mathrm{NO}_{2}$ for years 2013 to 2018 

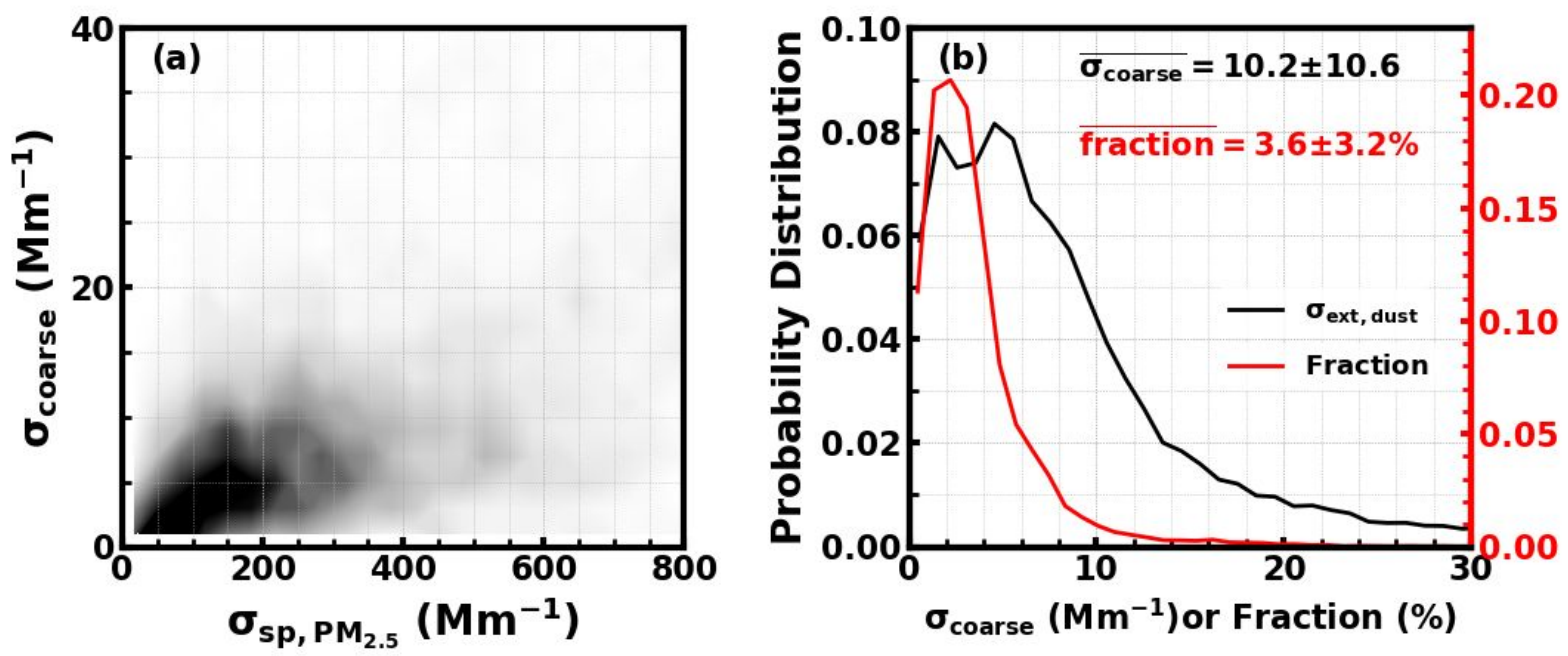

153 Figure S3 (a) The simulated $\sigma_{s p, P M_{2.5}}$ and $\sigma_{\text {coarse }}$ using particle number size distributions of 154 PM10 measured at eight sites on the North China Plain; (b) The Probability distribution of $155 \sigma_{\text {coarse }}\left(\right.$ black line) and its fraction (red line) to $\sigma_{s p, P M_{2.5}}$. 

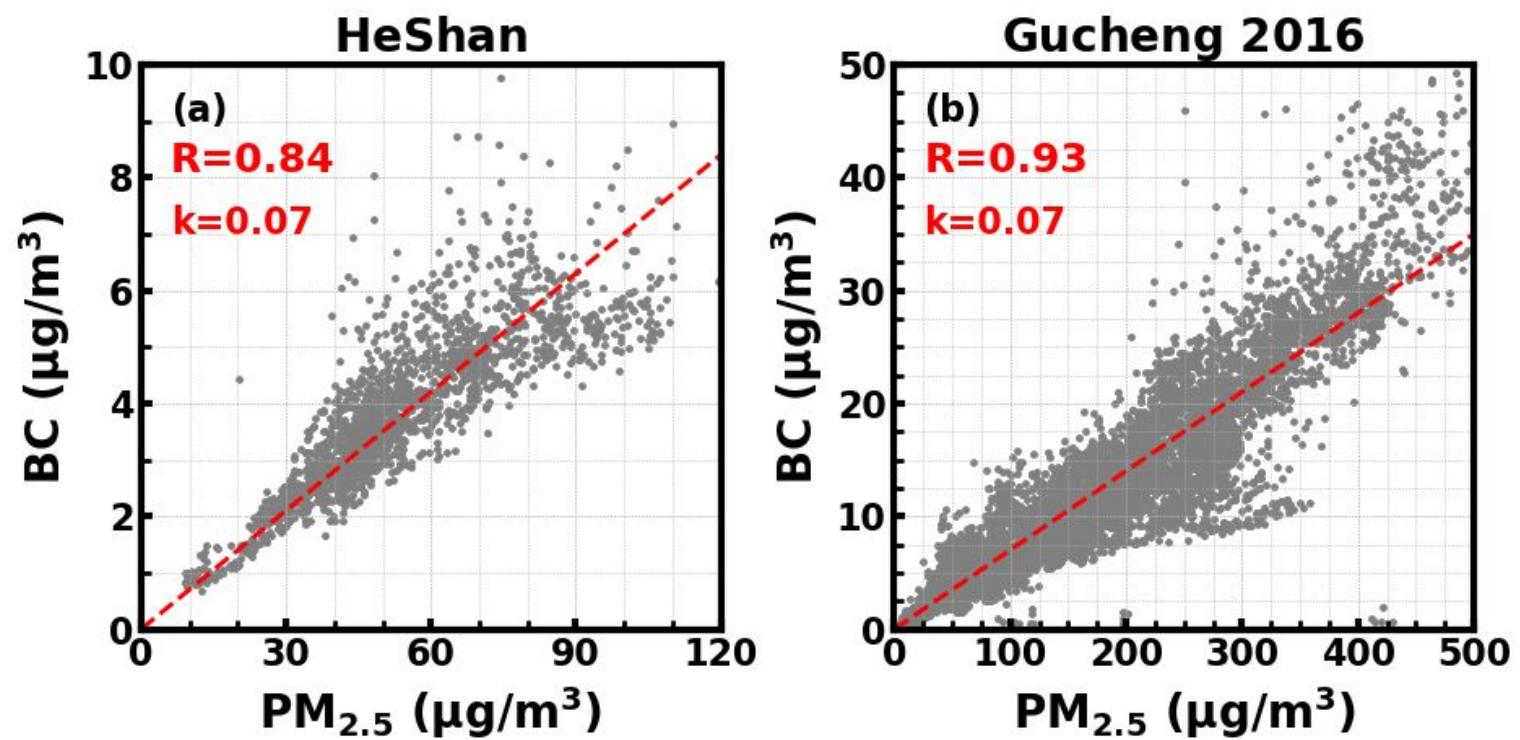

Figure S4. The relationship between mass concentrations of PM2.5 and BC at a) HeShan and b) Gucheng 2016. 

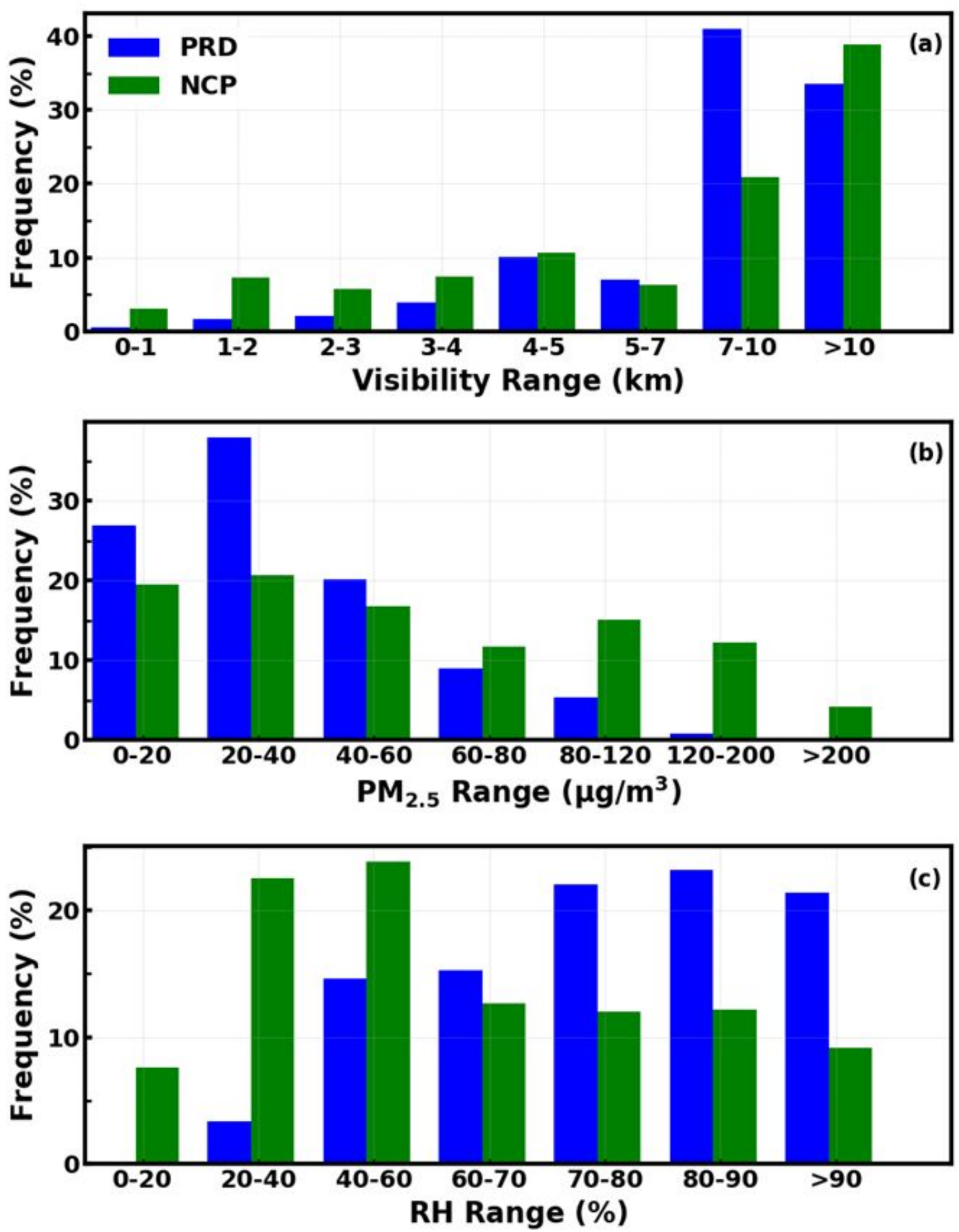
Confidential manuscript submitted to Environmental Science and Technology Letters

167 NCP (green) regions between 2013 and 2018.

168 

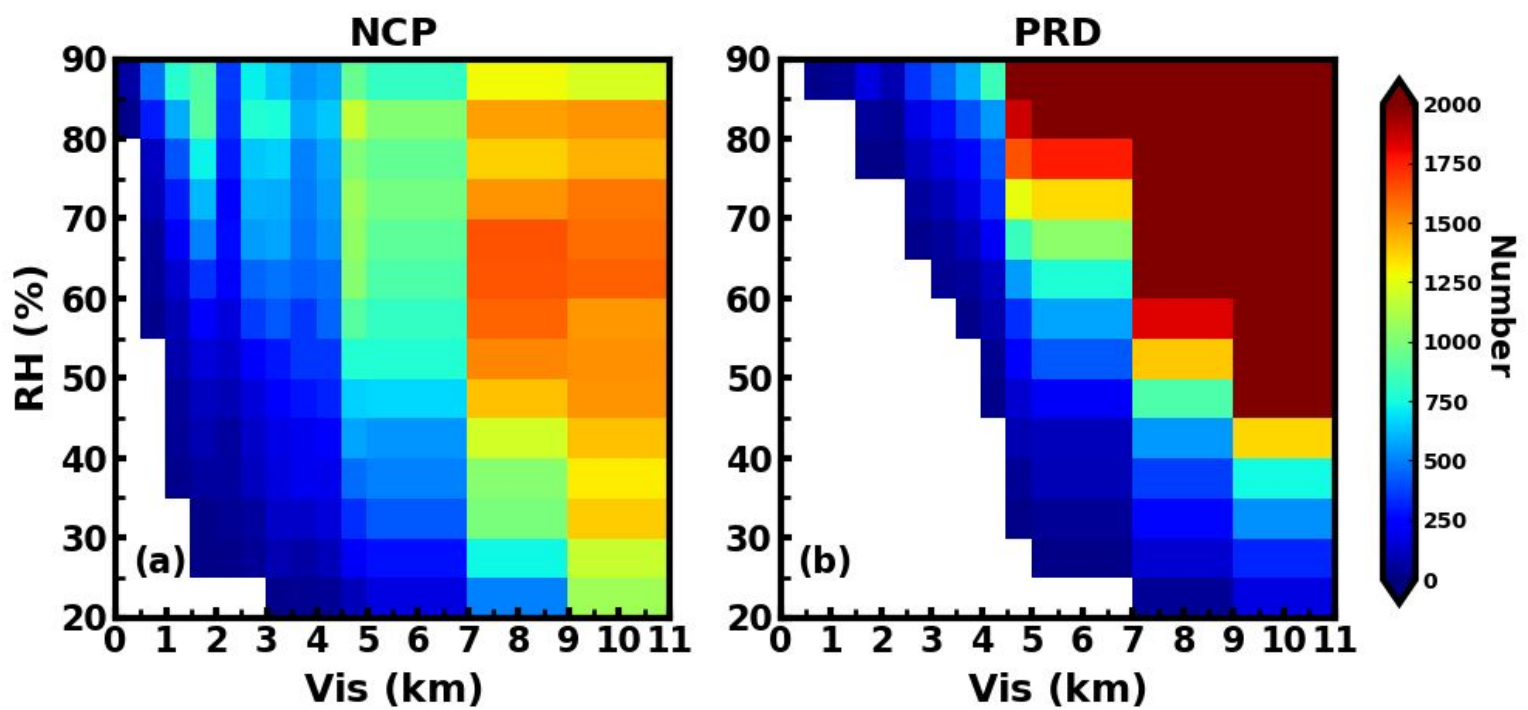

170 Figure S6 Number of data points under different RH and visibility ranges for NCP and PRD 171 regions. 

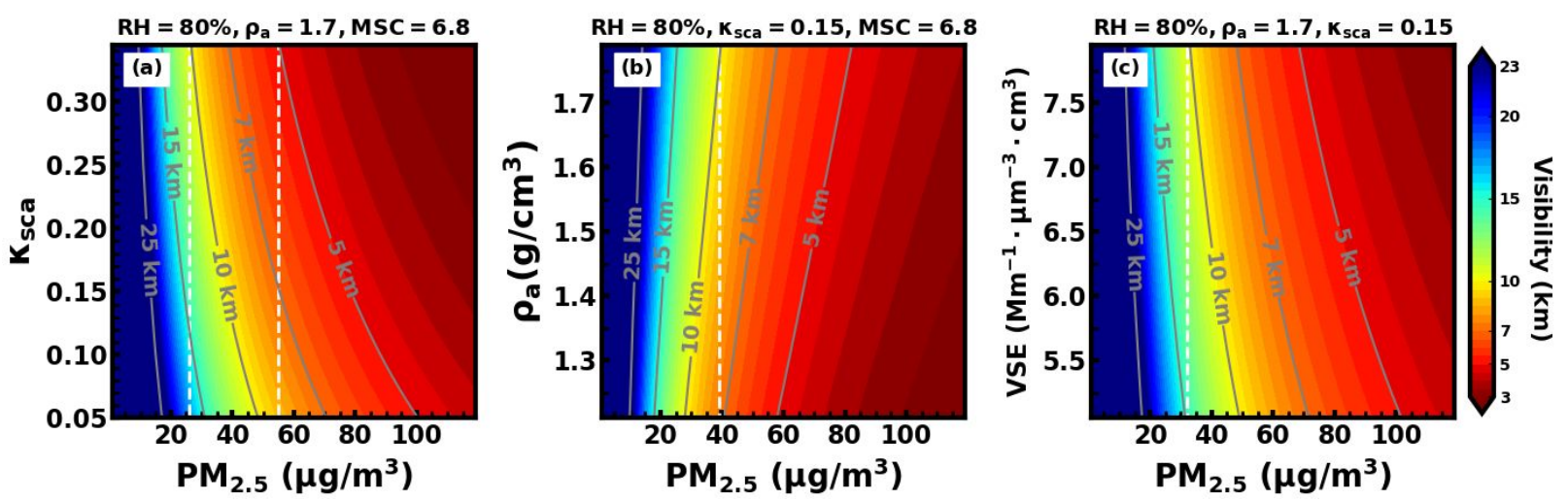

174 Figure S7. Variation of visibility with PM2.5 and a) aerosol optical hygroscopicity parameter $\left.175\left(\kappa_{\text {sca }}\right), \mathbf{b}\right)$ aerosol density $\left(\rho_{\mathrm{a}}\right)$ and c) Volume scattering efficiency (VSE)

176

177

178

179

180 

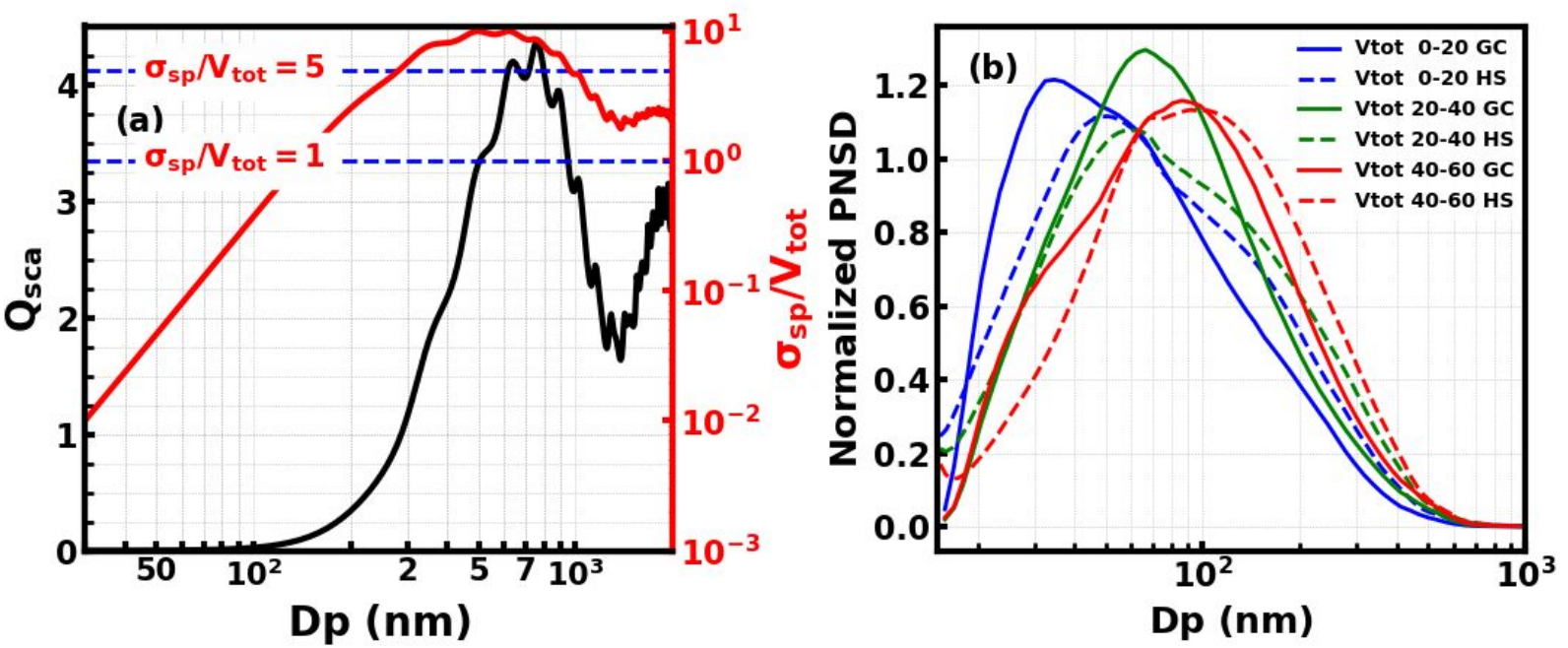

Figure S8. (a) Aerosol scattering efficiency $\mathrm{Q}_{\text {sca }}$ (black) and volume scattering efficiency (red) as a function of particle diameter (units of $\mathrm{Mm}^{-1} \mu \mathrm{m}^{-3} \mathrm{~cm}^{3}$ ); (b) normalized PNSD of GC2016 and Heshan campaigns under different aerosol volume concentrations levels. 

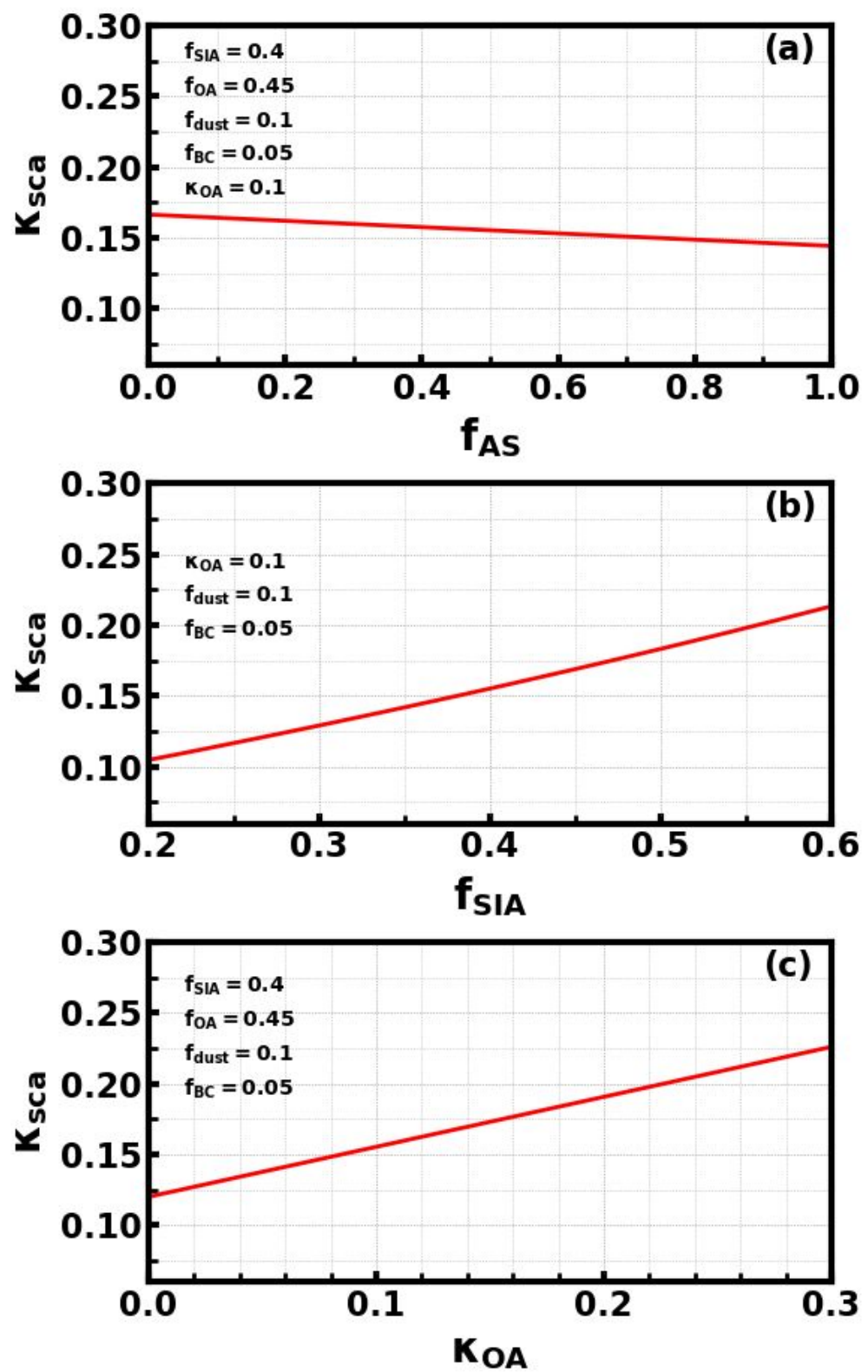

186

187

188

189
Figure S9 Changes in $\kappa_{\text {sca }}$ with varying (a) ammonium sulfate fraction among SIA, (b) secondary inorganic aerosol (SIA) fraction and (c) organic aerosol hygroscopicity $\left(\kappa_{\mathrm{OA}}\right)$. 


\section{References}

191 1. Chen, J.; Zhao, C. S.; Ma, N.; Liu, P. F.; Göbel, T.; Hallbauer, E.; Deng, Z. Z.; Ran, L.; 192 Xu, W. Y.; Liang, Z.; Liu, H. J.; Yan, P.; Zhou, X. J.; Wiedensohler, A., A parameterization of 193 low visibilities for hazy days in the North China Plain. Atmos. Chem. Phys. 2012, 12, (11), 49351944950.

195 2. Luan, T.; Guo, X.; Guo, L.; Zhang, T., Quantifying the relationship between PM2.5

196 concentration, visibility and planetary boundary layer height for long-lasting haze and fog-haze 197 mixed events in Beijing. Atmos. Chem. Phys. 2018, 18, (1), 203-225.

198 3. Deng, J.; Xing, Z.; Zhuang, B.; Du, K., Comparative study on long-term visibility trend 199 and its affecting factors on both sides of the Taiwan Strait. Atmospheric Research 2014, 143, (0), $200 \quad 266-278$.

201 4. Kuang, Y.; Zhao, C.; Tao, J.; Bian, Y.; Ma, N.; Zhao, G., A novel method for deriving 202 the aerosol hygroscopicity parameter based only on measurements from a humidified 203 nephelometer system. Atmos. Chem. Phys. 2017, 17, (11), 6651-6662.

204 5. Koehler, K. A.; Kreidenweis, S. M.; DeMott, P. J.; Petters, M. D.; Prenni, A. J.; Carrico, 205 C. M., Hygroscopicity and cloud droplet activation of mineral dust aerosol. Geophysical 206 Research Letters 2009, 36, (8).

207 6. Liu, X.; Cheng, Y.; Zhang, Y.; Jung, J.; Sugimoto, N.; Chang, S.-Y.; Kim, Y. J.; Fan, S.; 208 Zeng, L., Influences of relative humidity and particle chemical composition on aerosol scattering 209 properties during the 2006 PRD campaign. Atmospheric Environment 2008, 42, (7), 1525-1536. 